Céli Regina Jardim Pinto

Universidade Federal do Rio Grande do Sul

\title{
O feminismo bem-comportado de Heleieth Saffioti (presença do marxismo)
}

\begin{abstract}
Resumo: Neste texto, gostaria de eleger um momento da vida de Heleieth Saffioti, aquele que reputo seu ato de maior coragem: sendo uma socióloga marxista, tendo Florestan Fernandes como orientador, ter decidido escrever um trabalho de livre-docência sobre a mulher no Brasil, na década de 1960. É a partir desses encontros que será analisado o casamento entre o marxismo e o feminismo que Heleieth realizou em seu livro inaugural. Este artigo está dividido em duas partes: na primeira, apontarei as principais questões discutidas por Heleieth Saffioti em seu livro; na segunda, tratarei de um inimigo comum que aproxima Saffioti de duas mulheres centrais do feminismo da época, Simone de Beauvoir e Betty Friedan: Dr. Freud.

Palavras-choves: feminismo; marxismo; Saffioti; Beauvoir; Friedan; Freud.
\end{abstract}

Copyright (C) 2014 by Revista Estudos Feministas.
Feministas brasileiras de minha geração têm razões de sobra para homenagear Heleieth Saffiotti. Quer tenhamos privado com ela ou não, sabemos de sua força, de seu comprometimento com a causa feminista, de sua infinita capacidade de defender suas ideias. Foi um exemplo para todas nós que precisávamos de força e perseverança para a luta, que muitas vezes parecia um suceder de embates perdidos. Homenageá-la, falar de sua importância para os estudos de gênero no Brasil e do seu aguerrido comprometimento com a questão da violência contra a mulher não é uma tarefa difícil. Difícil é escolher um momento de sua vida.

Neste texto, gostaria de eleger um momento especial de Heleieth Saffioti, aquele que reputo seu ato de maior coragem: sendo uma socióloga marxista, ter decidido escrever um trabalho de livre-docência sobre a mulher no Brasil, em plena década de 1960, sob orientação de Florestan Fernandes.

Essa abordagem será dividida em duas partes: na primeira, apontarei os principais pontos discutidos por 
1 Em outra oportunidade, assim caracterizei o feminismo liderado por Bertha Lutz: "Em suma, se a luta das mulheres cultas e das classes dominantes se estruturava a partir da luta pelo voto, não era tão-somente porque esta se colocava como a luta do momento nos países centrais, mas também porque encontrava respaldo entre os membros dessa elite e conseguia respeitabilidade até da conservadora classe políitica brasileira. Era, portanto, um feminismo bem-comportado, na medida em que agia no limite da pressão intraclasse, não buscando agregar nenhum tipo de tema que pudesse pôr em xeque as bases da organização das relações patriarcais." (Céli Regina PINTO, 2003 p. 26).

${ }^{2}$ Heleieth SAFFIOTI, 1976, p. 14.
Heleieth Saffioti no livro que dá a público seu trabalho; na segunda, tratarei de um inimigo comum que aproxima Saffioti de Simone de Beauvoir e Betty Friedan, duas mulheres centrais do feminismo da época.

\section{O livro e suas circunstâncias}

Escrito entre os anos de 1966-1967 e publicado pela primeira vez em 1969, A mulher na sociedade de classes: mito e realidade é uma obra que amalgama três histórias: a pessoal, a do momento político e intelectual do Brasil e a do feminismo. A partir desses encontros, gostaria de analisar o casamento entre o marxismo e o feminismo que Heleieth realizou em seu livro inaugural.

Começo por um paradoxo do livro e da posição de Saffiotti: foi a primeira mulher a escrever um livro, dentro da academia, centrando sua análise na condição de dominação da mulher, ainda que se colocasse como não feminista devido aos pressupostos teóricos marxistas que adotava, o que chamo de segunda fase do feminismo bem-comportado brasileiro.'

Saffioti, mesmo quando tratou de temas que eram caros às duas grandes referências feministas até aquele momento, Simone de Beauvoir e Betty Friedan, cuidou de se afastar da posição dessas pensadoras para manter seu marxismo intacto. O paradoxo, pois, está posto: o primeiro grande texto feminista no Brasil foi escrito por uma mulher que era declaradamente não feminista. No prefácio, escrito em 1969 para a primeira edição do livro, Saffioti assim expressa sua posição:

Se esta obra não se dirige apenas às mulheres, não assume, de outra parte, a defesa dos elementos do sexo feminino. Não é, portanto, feminista. Denuncia, ao contrário, as condições precárias de funcionamento da instituição familiar nas sociedades de classe, em decorrência de uma opressão que, tão-somente do ponto de vista da aparência, atinge apenas a mulher. ${ }^{2}$

Mesmo com essa postura, Heleieth Saffioti foi pioneira, e não só no Brasil: seu livro antecedeu o pico da chamada segunda onda do feminismo, apesar de já circularem, no mundo ocidental, duas obras de grande repercussão: $O$ segundo sexo, de Simone de Beauvoir, publicado em 1949, e a Mística feminina, da americana Betty Friedan, publicado em 1963 e considerado um marco do movimento feminista norte-americano. Esses livros não tiveram influência marcante no trabalho de Heleieth. Seu contexto estava profundamente influenciado por outra problemática.

Nunca é demais lembrar que, após um período de radicalização política, o Brasil havia sofrido em 1964 um 
${ }^{3}$ Em uma entrevista à revista Estudos Feministas, Heleieth Saffioti conta com detalhes sua trajetória pessoal e intelectual durante esses anos (Estudos Feministas, Florianópolis, volume 19, número um, páginas 141-165, janeiro/abril 2011). duro golpe de estado, quando foi deposto o presidente constitucionalmente eleito e instaurado um governo militar, com censura, perseguições por razões ideológicas, prisões e cassações de mandatos políticos. Durante os últimos anos da década de 1950 e os primeiros de 1960, Saffioti fez sua formação, em meio a uma grande efervescência política. ${ }^{3}$ Tanto o meio intelectual como o político estavam, à época, profundamente influenciados pelas ideias marxistas de revolução e de terceiro mundismo. As revoluções russa e chinesa, e principalmente a cubana, eram vistas como modelos ou, pelo menos, possibilidades de diferentes arranjos políticos e econômicos.

O subdesenvolvimento do capitalismo do então chamado Terceiro Mundo, a pobreza e a ignorância de vastas parcelas da populações somavam-se ao golpe de estado, para formar um caldo de cultura que aproximava os intelectuais brasileiros do ideário revolucionário e do marxismo, considerado um seguro ancoradouro, em que políticos de esquerda e intelectuais encontravam explicação aparentemente científica para os acontecimentos que apontavam um futuro otimista.

O livro de Saffioti, desde seu título, é tributário dessas condições de emergência. Antes de ser uma obra feminista, Mulher na sociedade de classes... é um estudo marxista sobre o capitalismo subdesenvolvido, em que a mulher é vista como uma prova da distância entre a aparência e a essência na relação de dominação.

Além da obra de Marx referida ao longo de todo o livro, Saffioti esteve claramente influenciada pela literatura sociológica e historiográfica que era produzida no Brasil da época: Florestan Fernandes, seu orientador, havia publicado, nos primeiros anos da década de 1960, Ensaios de sociologia geral e aplicada (1960), Sociologia em uma era de revolução social (1963) e A integração do negro na sociedade de classe (1964); Caio Prado Junior publicou, em 1966, sua influente obra A revolução brasileira; Nelson Werneck Sodré, Formação histórica do Brasil (1963), Introdução à revolução brasileira (1963), As razões da independência (1965) e Ideologia do colonialismo (1965). Na área da economia, Celso Furtado, neste período, publicou alguns de seus mais importantes livros, como Desenvolvimento e subdesenvolvimento (1961); Formação econômica do Brasil (1963) e Subdesenvolvimento e estagnação na América Latina (1966). Esses autores são bastante citados ao longo do livro.

O livro de Saffioti está dividido em três partes. Na primeira, localiza a mulher na sociedade de classes e se utiliza largamente da obra de Marx. A tese central da autora é que a condição da mulher na sociedade, desde a segunda metade do século XVIII, decorre das necessidades do capitalis- 
${ }^{4}$ SAFFIOTI, 1976, p. 66.

${ }^{5}$ SAFFIOTI, 1976, p. 86-87. mo, que alterou as condições de vida da mulher. Ao se referir à nova posição da mulher, após o aparecimento do modo de produção, declara:

O aparecimento do capitalismo se dá, pois, em condições extremamente adversas à mulher. No processo de individuação inaugurado pelo modo de produção capitalista, a mulher contaria com uma desvantagem social de dupla dimensão: no nível superestrutural, era tradicional uma subvalorização das capacidades femininas traduzidas em termos de mitos justificadores da supremacia masculina e, portanto, estrutural, à medida que se desenvolviam as forças produtivas, a mulher vinha sendo progressivamente marginalizada das funções produtivas, ou seja, perifericamente situada no sistema de produção. ${ }^{4}$

A centralidade do capitalismo como motor de todas as formas de dominação leva Saffioti a minimizar a própria condição da mulher:

O processo de criação das condições de pleno emprego da força de trabalho feminina e masculina de uma sociedade estará, pois, na dependência da ação coletiva das duas categorias de sexo. E esta ação se liga, de uma parte, ao desenvolvimento das forças produtivas da sociedade e, de outra, ao grau de consciência que homens e mulheres atingem das contradições de sua época e das possibilidades de sua superação. ${ }^{5}$

Desta forma, Saffioti afasta-se completamente das ideias-forças defendidas pelo feminismo que ressurgia na década de 1960. A questão da mulher era vista por ela, com muita clareza, como uma manifestação, entre outras, da estrutura de classes. Pensar a dominação da mulher fora desse enquadramento seria tomar a aparência como essência. A autora é enfática ao afirmar:

Saffioti conclui que não é possível qualquer tipo de libertação para a mulher no contexto do capitalismo e que só o socialismo tinha uma natureza libertária capaz de dar fim à opressão feminina. Daí que a luta deveria ser uma luta de classes e não de gênero. Aponta também para a natureza pequeno-burguesa do feminismo, que viria reforçar a sociedade de classe. Em consequência, reduz a verdadeira luta feminista à luta pelo socialismo:

Na verdade não um feminismo autônomo, desvinculado de uma perspectiva de classe. O feminismo pequenobuguês constitui, no fundo e inconscientemente, dado que as chamadas <classes médias> caminham a reboque das classes sociais antagonicamente situadas no sistema de produção, um feminismo de classe dominante, pois tem fornecido inestimáveis subsídios à

324 Estudos Feministas, Florianópolis, 22(1): 321-333, janeiro-abril/2014 
${ }^{6}$ SAFFIOTI, 1976, p. 132.

7 SAFFIOTI, 1976, p. 177, grifo da autora. ideologia das sociedades competitivas sem classe e sem preconceitos de sexo. ${ }^{6}$

Com este pano de fundo marxista, Saffioti chega à segunda parte de seu livro, intitulado $A$ evolução da condição da mulher no Brasil. É bastante curioso que, para manter o mesmo argumento geral de que o capitalismo deteriorou a posição da mulher, ao analisar o Brasil, se valha de Weber para identificar a passagem de um sistema de casta para um sistema de classes sociais. Para a autora, o capitalismo se estabelece no país com a abolição da escravatura, quando se rompe o sistema de castas. Segundo ela, tal rompimento foi benéfico para as mulheres negras, mas não para as mulheres brancas:

[...] se a Abolição constituiu uma emancipação precária e incompleta, uma descensão relativamente ao homem negro. Extirpada a divisão de castas da sociedade brasileira, a determinação sexo ganha novo sentido, constituindo-se, na sociedade de classes em formação, como fora a raça na sociedade de castas e ainda o é, embora em menor grau, nas sociedades competitivas, no disfarce adequado das tensões sociais geradas pela implantação do sistema capitalista de produção plenamente constituído, apesar de não desenvolvido.?

Para avançar no entendimento do pensamento de Heleieth Saffioti sobre as manifestações do movimento feminista, é particularmente importante atentar para a forte adesão ao marxismo, o que a coloca, em alguns momentos, em sérias dificuldades. É o que ocorre no exemplo acima, quando precisa recorrer à categoria weberiana de casta para atribuir ao capitalismo uma espécie de 'culpa essencial' em relação à condição da mulher no Brasil, na passagem do século XIX para oXX.

A pesquisadora acolhe a conhecida ideia de que o Brasil importa ideologias alienígenas, que nada têm a ver com as necessidades locais, concepção popularizada na literatura sociológica como efeito de demonstração, e coloca as questões da emancipação feminina dentro desse cenário. Examinando a primeira metade do século XX, Saffioti é enfática na crítica ao feminismo brasileiro. As lutas das mulheres por direitos políticos (direito de votarem e serem votadas) e por melhores condições de trabalho foram vistas como questões pequeno-burguesas, que respondiam aos interesses do capitalismo. A proteção do trabalho feminino, conseguida no Estatuto da Mulher, foi interpretada como desnecessária e mesmo prejudicial:

O Estatuto da Mulher era, pois, um documento contraditório, se focalizado do ponto de vista feminista (sic). 
${ }^{6}$ SAFFIOTI, 1976, p. 275.
Admitia a redução do salário feminino da trabalhadora da empresa privada, quando em gozo de licença especial, período em que a mulher mais necessitaria dispor da totalidade de seus ganhos, compreendendo que as unidades produtivas, empenhadas na obtenção do lucro individual, não poderiam arcar inteiramente com o ônus da maternidade. Por outro lado, permitia às trabalhadoras de algumas categorias ocupacionais tomar, sem perda de salário, dois dias de folga por mês. Se, para a mulher já é difícil reduzir as diferenças que a separam do trabalhador homem, observando a legislação apenas imprescindível à maternidade, sua situação enquanto trabalhadora se torna ainda mais delicada e perigosa quando outras medidas legais discriminam. ${ }^{8}$

Saffioti entendia que medidas que melhorassem as condições de trabalho da mulher eram no máximo paliativas e correspondiam a um feminismo pequeno-burguês que não tomava em consideração as condições estruturais do país. A crítica da autora sempre se dirige a uma falta de perspectiva revolucionária do feminismo brasileiro, preocupado somente com direitos das mulheres e não com o sistema capitalista e a luta de classes. É interessante observar, ainda, a identificação que Saffiotti faz do chamado feminismo de esquerda, que, na verdade, nada mais era do que uma organização de mulheres, braço do PCB, que nada tinha de feminista. Saffioti dá grande importância a essa organização:

A luta dos movimentos femininos de 'esquerda' desenvolveu-se, precipuamente, em torno de acontecimentos políiticos contra a alta do custo de vida e, apenas secundariamente, em prol dos direitos da mulher. Assim, justifica-se o fato de que algumas associações de gênero tivessem tido existência efêmera. A União Feminina, por exemplo, fundada em 1934, mal teve tempo suficiente para obter um número razoável de adeptas dentre as mulheres intelectuais e operárias. Como parte integrante da Aliança Nacional Libertadora, foi colocada fora da lei em 1935, tendo todas as suas dirigentes sido presas, algumas das quais permaneceram mais de ano sem liberdade. ${ }^{9}$

A avaliação positiva feita em relação ao feminismo no Brasil relaciona-se a lutas que nada têm a ver com o feminismo, tal como tem sido entendido por estudiosas e estudiosos do tema. O mito da mulher na sociedade de classe é, para ela, a própria existência da problemática feminina. Naquele momento, ela entendia que a única luta real a ser travada era a de classes, que levasse à conscientização e ao socialismo, como fica claro no momento final da segunda parte do livro:

O 'feminismo socialista', ou simplesmente 'esquerdizante', mesmo nas suas manifestações exclusivas ou 
10 SAFFIOTI, 1976, p. 280. quase exclusivamente práticas, sem pretensões teorizantes, como ocorreu no Brasil, representa, inegavelmente, uma forma de consciência mais plena que seu correspondente pequeno-burguês. Assumindo uma postura altamente crítica em relação ao status quo capitalista, foi capaz de tomar os problemas da mulher simplesmente como uma dimensão de uma totalidade social mais rica de determinações e localizar, nestas, as que deviam merecer atenção no plano imediato. ${ }^{10}$

Apesar desta postura, que pode ser vista até como antifeminista nas duas primeiras partes do livro, na terceira parte, sem abandonar a perspectiva marxista, a autora passa a discutir temas que estão próximos à discussão feminista internacional, como a teoria psicanalítica e as teses da antropologia. A questão da psicanálise também é objeto de atenção de Simone de Beauvoir e Betty Friedan, razão pela qual será analisada aqui com especial atenção.

Antes de entrar nesse tema específico, cabe anotar a postura de Saffioti em relação a essas duas autoras. Saffioti conhecia os dois livros e até cita o de Friedan em sua edição francesa; entretanto, não os considera em sua discussão, nem mesmo para contrariá-los.

Ao longo das 375 páginas de texto, Saffioti cita quatro vezes Friedan e três Beauvoir. Nessas citações, não há nenhuma discussão ou reconhecimento da importância, ou, pelo menos, da polêmica e repercussão que essas obras causaram. No que concerne a Friedan, Saffioti apenas remete duas vezes ao livro sem nenhuma explicação, como para lembrar ao leitor que o que está afirmando pode ser encontrado na obra da feminista americana. Apenas uma vez, na nota 75 (página 80), usa o texto de Friedan para argumentar que as mulheres que não trabalham fora de casa usam muito mais tempo que as que trabalham para fazer as tarefas domésticas. Em relação à Simone de Beauvoir, Saffioti é ainda mais econômica. Cita uma frase famosa dela: "o problema das mulheres sempre foi um problema dos homens" e, em duas outras oportunidades, faz ligeiras críticas. Na página 79, declara ser impossível a solidariedade entre todas as muIheres, independentemente de classe, "como querem alguns". Após essa afirmação, remete à obra de Beauvoir, sem qualquer explicação adicional. Em outro momento, ao criticar a violência das feministas inglesas, que não teriam entendido sua real condição de opressão, ou seja, a opressão de classe, remete a Beauvoir e afirma que, embora ela negue a violência, acaba por descrever cenas que a comprovam.

A forma como Saffioti relaciona-se com essas duas figuras centrais do feminismo em seu livro é bastante reveladora das condições de emergência nas quais escreveu sua 
"Até hoje, em certos espaços acadêmicos, existe um certo tipo de 'patrulha' em relação a alguns autores não marxistas. Talvez Michel Foucault e Hannah Arendt sejam os mais populares 'proibidos' em alguns redutos marxistas brasileiros ainda hoje. tese. Aqui não interessa saber se Heleith Saffioti gostava ou não dessas autoras, mas as condições que elas tinham para frequentar teses de livre-docência realizadas nos departamentos de sociologia no Brasil, principalmente, nas grandes universidades paulistas da época. As ausências se explicam por razões distintas: Simone de Beauvoir tinha um ativismo político muito forte. Junto com seu companheiro, Sartre, foi um presença bastante constante na União Soviética. Ambos admiravam a revolução chinesa e se manifestaram fortemente contra o colonialismo francês na Argélia. Haviam, inclusive, visitado o Brasil no ano de 1960, quando estiveram no interior de São Paulo, na UNESP de Araraquara. Apesar disso, o cenário era completamente dominado pelo marxismo e, mais do que isto, pela incorporação da pretensão científica e, portanto, exclusiva, do materialismo histórico como explicação do social. Beauvoir, uma existencialista, trazia para a linha de frente a dominação da mulher, não entendendo esse acontecimento como derivação da dominação de classe.

A resistência a Betty Friedan é ainda mais fácil de entender, pois era uma mulher liberal, norte-americana, que causava mal-estar, tanto por suas ideias como por suas atitudes públicas. Para os intelectuais e as intelectuais brasileiras, havia grande dificuldade de aceitar, ou mesmo reconhecer, como do mesmo campo, posturas que se afastavam de qualquer discussão de outra forma de opressão que não a da mulher. O movimento chamado women libereration, aparecido nos Estados Unidos nos primeiros anos da década de 1960, soava no Brasil quase como uma agressão. Vale lembrar o antiamericanismo atávico dos intelectuais de esquerda brasileiros à época. ${ }^{11}$

Mesmo que ela não se tenha ocupado dos famosos livros de Simone de Beauvoir e Betty Friedan, é significativo encontrar, na obra das três autoras, tão distantes entre si, um inimigo comum: Dr. Sigmund Freud.

\section{O inimigo comum: Dr. Sigmund Freud}

Com argumentos muito diversos e partindo de posturas também muito distintas, as três autoras em tela atribuem a Freud uma espécie de condenação da mulher à inferioridade, por sua essência. Beauvoir, certamente a que mais profundamente entendeu Freud, acusa o psiquiatra vienense de conceitos rígidos para definir a sexualidade feminina a partir do estudo da sexualidade do homem. À mulher Freud teria negado uma libido com características próprias e dado a um fato social - a soberania do pai que levaria à inveja do pênis - uma condição de natureza. Beauvoir enfatiza:

Entre as mulheres e homens da burguesia, a solidariedade de classe se estabelece inteiramente; nada há 
${ }^{12}$ Simone BEAUVOIR, 1967, p. 132

${ }^{13}$ BEAUVOIR, 1967, p. 67.

${ }^{14}$ Betty FRIEDAN, 1963, p. 100

\footnotetext{
15 Betty FRIEDAN, 1971, p. 109.
}

que mine sua coesão, pois a mulher se beneficia da apropriação da mais-valia criada pelo trabalho do produtor imediato por parte de seu marido. Na classe trabalhadora a solidariedade é, às vezes, turvada por uma semi consciência entre os sexos. A mulher proletária e dos estratos médios da sociedade disputa com os homens de sua mesma posição social os postos que lhe possam garantir o sustento. ${ }^{12}$

Como existencialista, Beauvoir faz uma severa crítica ao conceito freudiano de inconsciente, que novamente determinaria a vida das mulheres sem lhes deixar possibilidade de escolha:

é essa noção de escolha que o psicanalista rechaça, mais violentamente em nome do determinismo do 'inconsciente coletivo'. Este forneceria ao homem imagens feitas e um simbolismo universal. ${ }^{13}$

Friedan, além de compartilhar com Beauvoir a mesma ideia sobre teoria da inveja do pênis, avança em sua crítica, atribuindo às teorias de Freud a obsessão por sexo da Europa vitoriana e sua hipocrisia moral, e afirma que ele desenvolveu suas teorias com base em sua própria vida:

Esta submissão ilimitada da mulher, aceita sem discussões pela cultura de Freud, a falta de oportunidade para ação independente e identidade pessoal parece muitas vezes ter gerado o embaraço e a inibição da esposa e a irritação do marido que caracterizou o casamento do sábio. Segundo Jones, a atitude de Freud em relação às mulheres <<poderia ser, provavelmente, chamada antiquada e seria fácil atribuí-la ao seu ambiente social e ao período em que viveu a adolescência, mais que a fatores pessoais >>..$^{14}$

A feminista americana faz uma apreciação muito particular da adoção da teoria psicanalítica freudiana nos Estado Unidos do pós-guerra. Critica fortemente a vulgarização e a popularização da psicanálise, responsabilizando-a pelo que chama de contrarrevolução das mulheres naquele país:

Mas a prática da psicanálise como terapia não foi a principal responsável pela mística feminina. Esta foi criação de escritores, editores de publicações para as massas, pesquisadores de publicidade, apoiados pelos divulgadores e tradutores do pensamento freudiano em colégios e universidades. Teorias freudianas e pseudofreudianas espalharam-se por toda parte, como cinzas de um vulcão. A sociologia, a antropologia, e até o estudo da história e literatura ficaram impregnados e transfigurados pela ideia freudiana. ${ }^{15}$

Saffioti compartilha com Beauvoir e Friedan as críticas a Freud, apesar de nunca citá-las neste particular. Como já 
${ }^{16}$ SAFFIOTI, 1976, p. 295

17 SAFFIOTI, 1976, p. 296.

foi dito antes, o fato de se declarar não feminista desde a introdução de seu livro, a leva a não incorporar em seu texto nenhuma discussão feminista internacional. Na crítica a Freud, Saffioti está muito próxima de ambas ao se referir ao essencialismo da teoria e à posição de passividade reservada à mulher:

Ao mito da vassalidade feminina, habilmente nutrido até os dias atuais, sobretudo pela imprensa chamada do coração, Freud acrescentou o mito da passividade. Assimilando o ativo ao viril e o passivo ao feminino, a Psicanálise freudiana legitimou cientificamente 0 velho mito, promovendo sua ampla aceitação nas sociedades baseadas na ciência e na tecnologia científica. Assim acabou o mito da passividade feminina por se transformar numa verdadeira profecia autorealizadora. Acreditando na passividade como propriedade intrínseca da personalidade feminina, 'verdade' afirmada pelos livros científicos, propalada e reinterpretada pela literatura de divulgação e pela 'imprensa do coração', a mulher se definiu, de fato, como um criatura passiva, ratificando suas concepções através do comportamento manifesto. ${ }^{16}$

É surpreendente a coincidência entre a posição de Saffioti e a de Friedan no que diz respeito à questão da passividade, bem como, e principalmente, à crítica da vulgarização da psicanálise na imprensa dirigida às mulheres. É original, entretanto, a crítica de Saffioti a Freud no que concerne à falta de atenção para a sociedade de classes. Se, para Friedan, as analisadas eram as mulheres vitorianas, para Saffiotti, eram as burguesas:

Mesmo admitindo-se que as neuroses constatadas por Freud, na mulher européia do fim do século XIX e princípio do XX, se produzissem na média da sociedade austríaca de então, estando todas na mesma fase de evolução, não caberia generalizar conclusões. As clientes neuróticas de Freud pertenciam à burguesia e, portanto, não representavam a sociedade em sua totalidade. $\mathrm{O}$ que Freud constatou nestas nem sequer constituía um dado do comportamento da mulher proletária da Europa de então. A <mulher universal $>$ tanto como o <homem universal > são criações mentais inexistentes no terreno factual. Existem, isto sim, seres humanos condicionados pela situação histórico-social em que vivem e, neste contexto, e só neste, devem ser observados e explicados. ${ }^{17}$

Não é difícil entender porque o feminismo teve, principalmente nas suas primeiras manifestações da segunda onda, uma postura tão severamente crítica à psicanálise. Freud, machista ou não em sua vida pessoal, sexista ou não em sua teoria, expôs organizadamente a condição submissa 
e passiva da mulher. Esta condição é, inclusive, reconhecida pelas feministas, embora seja identificada por todas como uma condição externa, provocada pelo outro, que não constituía a mulher como sujeito. Havia uma ingenuidade no feminismo, assim como havia no marxismo que construía o dominado (classe social ou mulher) como o inocente, o puro, o depositário de todas as esperanças. Freud interrogava essas posturas com muita veemência, trazendo para o centro da discussão o inconsciente e a sexualidade. Daí se justifica que posturas tão diversas como as de Saffioti, Beauvoir e Friedan tratem de Freud com um inimigo comum.

\section{Nota final}

Heleieth Saffioti foi uma feminista bem-comportada. Quando analisei a trajetória de Bertha Lutz nas primeiras décadas do século XX, chamei seu feminismo de bem-comportado, pois se negava a expressá-lo como luta pelo lugar até então exclusivo do homem. Somar e cooperar, trazer a voz feminina para ajudar, era a base de seu discurso, pois, por razões muito diferentes da sufragista bem-comportada, o país chegou da mesma forma na segunda onda do feminismo, através de uma de suas mais importantes manifestações inaugurais: o livro de Heleieth Saffioti. O sentido de bemcomportado, apesar da distância abismal entre as posições ideológicas das duas personagens e a distância no tempo, é o mesmo. Nos dois casos, os posicionamentos, ainda que não fossem entusiastamente acolhidos, encontravam espaços para se exprimirem com legitimidade. Tanto os parlamentares da Primeira República como a sociologia paulista da década de 1960 certamente prefeririam não receber, em seus gabinetes, Bertha Lutz ou Heleieth Saffioti, mas, todavia, as recebiam. E assim agiam não porque fossem homens comprometidos com questões de direitos da mulher, mas porque ambas vestiam uma roupagem que as tornavam aceitas. Nenhuma usou disfarces, não portavam fantasias, eram trajes dentro dos quais se sentiam muito à vontade. Saffioti declarouse não feminista, escreveu um livro sobre a mulher para provar que, em última instância, ela não era uma questão central, que a submissão estava determinada à condição de classe. Quem estava subordinada era a classe proletária, não a muIher. Sob a orientação de Florestan Fernandes, em um ambiente dominado pelas obras de Caio Prado Junior, Nelson Werneck Sodré e Celso Furtado, em meio à derrota das forças de esquerda para o regime militar, o feminismo possível era o bem-comportado, que pode encontrar, mesmo com dificuldade, espaços de expressão.

Heleieth Saffioti foi uma intelectual e feminista que não soube se envolver pela metade, que defendeu suas 
causas com garra, audácia e um raro sentido de responsabilidade, tanto quando representou o feminismo bemcomportado da década de 1960 quando, após esse período, ao longo de sua vida, tornou-se uma das mais dedicadas e importantes lideranças de um feminismo deliciosamente mal-comportado.

\section{Referências}

BEAUVOIR, Simone. Segundo Sexo. São Paulo: Difusão Europeia, 1967.

FERNANDES, Florestan. A Integração do Negro na Sociedade de Classe. Porto Alegre: Globo, 1964. Ensaios de Sociologia Geral e Aplicada. São Paulo: Livraria Pioneira Editora, 1960. Sociologia em Uma Era de Revolução Social. Rio de Janeiro: Cia Editora Nacional, 1963.

FRIEDAN, Betty. A Mística Feminina. Pretópolis: Vozes, 1971.

FURTADO, Celso, Desenvolvimento e Subdesenvolvimento. Rio de Janeiro: Fundo de Cultura, 1961. . Formação Econômica do Brasil. Rio De Janeiro: Fundo de Cultura, 1963. Subdesenvolvimento e Estagnação na América Latina. Rio de Janeiro: Civilização Brasileira, 1966.

PINTO, Céli Regina. Uma História do Feminismo. São Paulo: Perseu Abramo, 2003.

PRADO JUNIOR, Caio. A Revolução Brasileira. São Paulo: Brasiliense, 1966.

SAFFIOTI, Heleieth. A Mulher na Sociedade de Classe: Mito e Realidade. Petrópolis: Vozes, 1976.

SODRÉ, Nelson Werneck. As Razões da Independência. Rio de Janeiro: Civilização Brasileira, 1965. . Formação Histórica do Brasil. São Paulo: Civilização Brasleira, 1963. . Ideologia do Colonialismo. Rio de Janeiro: Civilização Brasileira, 1965 Introdução à Revolução Brasileira. Rio de Janeiro: Civilização Brasileira, 1963.

[Recebido em 3 de maio de 2012 , reapresentado em 2 de abril de 2013 e aprovado em 18 de abril de 2013]

The Well-Behaved Feminism of Heleieth Saffioti (the Presence of Marxism) Abstract: In this text, I focus on a moment in Heleieth Saffioti's life which I deem as the one of her most courageous: to choose, as a Marxist sociologist, advised by Florestan Fernandes, the subject of women in Brazil for her Habilitation (Livre Docência) thesis in the 1960s. This combination establishes the point of view from which I will analyze the marriage between Marxism 
and feminism that Heleieth arranged in her first book. The article is divided in two parts: in the first one, I will point out the main issues discussed by Saffioti in her book; in the second part, I will be concerned with a common enemy, Dr. Freud, who put together Saffioti, and two key feminist women at the time, Simone de Beauvoir and Betty Friedan.

Key Words: Marxism; Feminism; Saffioti; Beauvoir; Friedan. 